\title{
GESTÃO ESTRATÉGICA DE RECURSOS HUMANOS NA ERA DA TECNOLOGIA DA INFORMAÇÃO E DA GLOBALIZAÇÃo
}

\author{
Lidia Eugenia Cavalcante
}

\begin{abstract}
Resumo
Trata sobre as alterações provocadas na gestão de recursos humanos para um novo mercado global, baseadas na capacitação profissional e educação continuada, exigências da sociedade do conhecimento. Aborda questões referentes às mudanças organizacionais, com base nos novos paradigmas da modernidade e competitividade do mercado mundial. Apresenta algumas considerações sobre o mercado da informação nas empresas em processo de mudança e seu impacto em áreas de decisões estratégicas empresariais. Assim, as novas tecnologias de informação, o capital humano e gestões estratégicas compreendem os principais fatores de competitividade e adequação à modernidade ou sociedade do conhecimento.
\end{abstract}

\section{Palavras-chave}

Gestão de recursos humanos; Tecnologia da informação; Mercado global; Sociedade do conhecimento.

\section{INTRODUÇÃO}

A sociedade tem vivenciado profundas transformações ocasionadas por revoluções que mudaram a forma de pensar, viver agir e produzir em diferentes contextos da atividade humana (política, econômica, social e cultural). A transição econômica, significativamente marcada pela Revolução Industrial, iniciada em meados do século XVIII na Inglaterra e proliferando-se pelo mundo todo, funcionou como cenário de uma nova realidade no mundo dos negócios, através 
do capitalismo e da revolução nos meios de produção e nos processos de trabalho pela mecanização e produção em massa. Essas transformações evidenciaram também conflitos entre os interesses de classes e grandes alterações sociais, marcando assim, o triunfo da chamada sociedade industrial.

Todavia, a valorização dos produtos manufaturados e dos processos de produção industrial, possibilitaram a divisão do trabalho, favorecendo o crescimento do capital e a introdução de máquinas para a realização das tarefas, em substituição à força física humana. Esse período, marcado por grandes contradições, apresenta também como característica a exploração dos trabalhadores assalariados e a formação de grandes centros urbanos ao redor das diferentes atividades econômicas e industriais.

Por muito tempo, a geração de riquezas e de capital esteve nas mãos de empresas dotadas de maquinário para produção em massa de produtos que, de alguma forma, eram consumidos, sem grandes exigências em termos de qualidade, pelos consumidores.

Contudo, diante das características histórico-sociais apresentadas pela Revolução Industrial e do processo de crescimento humano, chegou-se a uma nova revolução gerada pelo desenvolvimento científico e tecnológico, a produção do conhecimento e a constituição de novos saberes e idéias. Todos esses avanços tornaram- se o grande salto para a construção de um novo tempo histórico, de novos paradigmas, conceitos, exigências e metas, tanto empresariais quanto sociais.

\section{ERA TECNOLÓGICA E SOCIEDADE DO CONHECIMENTO}

Nas últimas décadas, presenciamos grandes e históricos avanços. Saímos de uma economia industrial para uma economia de informação e de transformação. Os avanços científicos e tecnológicos têm mudado radicalmente o conceito de capital, poder, mercado, organização e valor. As empresas com grandes extensões territoriais, elevado número de empregados e maquinário, não são mais sinônimos de força ou potência econômica. A forma como passaram a operar e os modelos de produção e de comercialização de bens e serviços foram radicalmente afetados. $O$ cliente passou a ser visto como parte primordial do processo, não mais como mero consumidor, mas adquiriu grande poder de decisão. Para o capital humano, tornou-se fundamental o acompanhamento desse processo através da qualificação profissional e do desenvolvimento da criatividade, fundamental à competitividade e à produtividade.

O processo de definição de estratégias de mudanças passa necessariamente pelo fator informação como elemento essencial à tomada de decisão. Informação não apenas vista como volume de dados Inf.Inf., Londrina, v. 5, n. 2, p. 139-147, jul./dez. 2000 
apresentados à gerência ou diretoria, mas como recurso indispensável ao desenvolvimento de qualquer atividade, desde a execução da mais simples tarefa ao posicionamento competitivo no mercado e grandes decisões administrativas.

\begin{abstract}
A informação e a tecnologia da informação podem ser analisadas em termos da sua capacidade de contribuir para mudanças no poder relativo de barganha de clientes e fornecedores; para criar, remover ou contornar barreiras à entrada e para diferenciar empresas de seus concorrentes no mesmo segmento. A informação também oferece novas alternativas para a configuração de cadeias de valor e para alcançar economias diferenciadas de escala e de escopo. (McGee \& Prusak, 1994, p.55).
\end{abstract}

Numa nova abordagem organizacional, a tecnologia da informação compreende uma tendência global de processos de gestão estimulando a competitividade no ambiente empresarial, o que cada vez mais acelera a capacidade de posicionamento de mercado para o enfrentamento das exigências e complexidade do atual quadro econômico e das recentes tendências mundiais.

Nesse contexto de globalização de mercados mundiais e monitoramento de ambientes internos e externos, as empresas tendem a investir cada vez mais em sistemas de informação como estratégia de competitividade e apoio a decisões, cujo principal objetivo é orientar diretores, gerentes, economistas, administradores, pessoal de marketing e muitos outros especialistas que lidam com o cenário e o negócio da organização, no sentido de apresentar informações atualizadas sobre mercado, economia, política, investimentos financeiros, novas tecnologias, produtos, serviços, clientes, concorrentes, fornecedores e meio ambiente, além de projeções de situações que possam afetar o ambiente empresarial, auxiliando na tomada de decisões futuras e na descoberta de novas possibilidades de mercado, aumentando a competitividade empresarial.

Nesse processo é que surge um promissor campo de atuação para o profissional da informação em parceria com outros profissionais e especialistas que já se posicionaram no mercado empresarial. Todavia, o conhecimento do bibliotecário em termos de documentação, fontes de informação, pesquisa, processo de comunicação de dados e disseminação seletiva de informação poderão ser o diferencial na simplificação, agilização e eficácia na área de informação organizacional.

Para uma sociedade do conhecimento, estratégias no uso da informação tornam-se fundamentais, pois as vantagens competitivas passaram a ser baseadas no uso desta como matéria-prima indispensável à tomada de decisões para alcançar posição de destaque, bem como para obtenção de recursos e aumento de potencial, tanto científico e tecnológico, quanto 
humano.

A economia do conhecimento representa ganhos notáveis para a sociedade moderna em relação à pesquisa científica, à organização econômica e social, à produção de bens e serviços, à educação - essencial nesse processo, e à qualidade de vida da população, porquanto significa o esforço humano para produzir melhores resultados respondendo a questões estratégicas de natureza ambiental, estrutural e social.

A dinâmica da informação, geradora de grandes potências no mundo todo, destruindo fronteiras através do uso de tecnologias avançadas, das redes de comunicação e da economia global deve estar aliada ao principal fator gerador desse crescimento: o capital humano, característica marcante da chamada sociedade do conhecimento e recurso essencial para que mudanças possam realmente acontecer.

Para Araújo citado por Wood Jr.,

Modernização é o processo pelo qual a sociedade incorpora novas formas organizacionais e tecnologias físicas e sociais que permitam atingir de maneira mais adequada novos objetivos. Mudança organizacional é qualquer alteração significativa, articulada, planejada e operacionalizada por pessoal interno ou externo à organização, que tenha o apoio e a supervisão da administração superior e atinja, integralmente, os componentes de cunho comportamental, tecnológico e estratégico. (1995, p. 25).

Atualmente, a dinâmica das mudanças passa prioritariamente pelo pontencial humano aliado ao raciocínio sistêmico, ao trabalho em equipe, à inovação e à qualificação profissional, representando a grande força para acelerar e administrar as alterações com muito mais competência e eficácia diante da complexidade instaurada nas sociedades do mundo global.

\section{CAPACITAÇÃO PROFISSIONAL versus CAPACITAÇÃO TECNOLÓGICA}

No processo de globalização, em uma economia orientada pela informação, as empresas têm buscado modernizar-se através da aquisição de computadores de última geração, equipamentos de alta tecnologia para automatizarem seus processos e garantirem qualidade, produtividade e competitividade. Entretanto, o principal investimento de uma organização que deseja tornar-se competitiva deverá ser em seu capital humano, garantindo a capacitação e a atualização profissional, adicionadas à educação formal e continuada, à formação de gestores, à descoberta de talentos e de idéias e à satisfação de necessidades. Nesse sentido, várias posturas têm sido adotadas por empresas como estratégias de crescimento, percorrendo os mais variados e possíveis caminhos: transformação de empregados em parceiros, apoio à 
geração e desenvolvimento de novas idéias, gestão participativa, gestão holística e organizações de aprendizagem, entre outras.

Essas propostas, entretanto, não são simples de serem adotadas como parecem, visto que muitas empresas esbarram na questão da cultura organizacional, crenças, valores e premissas que obstruem o processo de mudança, não podendo ser facilmente transformadas, pois estabelecem processos históricos antigos e que precisam ser trabalhados na perspectiva de triIharem novos caminhos. Essas visões conservadoras são comuns em empresas familiares e/ou nacionais tornando difícil a adaptação em mercados maduros, dinâmicos e em processo de mudança.

Muitas empresas buscam o caminho da modernização pela política de "portas abertas", eliminação de níveis hierárquicos e outros programas visando maior envolvimento dos funcionários através da gestão participativa. Para tanto, é necessário compreensão dos objetivos que se quer atingir de modo a se chegar a uma sintonia de propósitos entre todos os envolvidos no processo. É preciso compreender que mudanças devem ser introduzidas de forma gradual, porém, transformando significativamente os padrões culturais e as relações de poder nas organizações.

Outra questão fundamental à competitividade é o monitoramento permanente do ambiente externo à organização propiciando análises de seu referencial competitivo em relação ao mercado como: capital humano, clientes, tecnologias, marketing, processos produtivos e gerenciamento estratégico da informação. As empresas em melhores condições de competir no mercado apresentarão o referencial externo como recurso-chave de investimento para manter-se em posição estratégica.

\section{VISÃO ESTRATÉGICA: A FORÇA PRO- PULSORA DA MUDANÇA}

A mudança de paradigmas freqüentemente anunciada nos novos tempos tem afetado significativamente as diferentes áreas do conhecimento humano, na política, na economia, na educação, na cultura, no lazer e na cidadania. Compreender tal dinâmica e seus processos é buscar formas de agir sobre a realidade que se apresenta em uma visão de futuro contrapondo-se a idéias ultrapassadas.

Em face de uma nova visão estratégica e plural, marcada por diferentes olhares e sujeitos plurais dessa nova história, inserem-se formas inovadoras de gestão organizacional, administração participativa e novas tendências que geram transformações individuais e coletivas afetando relações, cenários e processos desse novo ambiente de potencialidade empreendedora e informacional.

Segundo Crawford (1994, p.16), 
Já se tem mais conhecimento das causas destas transformações no mundo do que se pode imaginar. Historiadores econômicos, ao estudarem o desenvolvimento da economia mundial e, particularmente, o desenvolvimento dos países industrializados nos últimos 250 anos, desenvolveram um modelo de como as economias e as sociedades evoluem. O modelo é o seguinte: novos conhecimentos levam a novas tecnologias, as quais, por sua vez, levam a mudanças econômicas; que, consequentemente, geram mudanças sociais e políticas, as quais, em última instância, criam um novo paradigma ou visão de mundo. Este modelo pode ser utilizado para explicar as dramáticas mudanças econômicas, sociais e políticas que vêm ocorrendo no mundo.

Percebe-se, todavia, que essas mudanças são tensas e turbulentas pois derrubar as fronteiras do poder e os muros das diferenças econômicas e sociais necessita de uma força propulsora que gere uma transformação ampla através da visão estratégica do todo baseada no capital humano, no conhecimento e nos investimentos destinados ao homem.

Para maior parte da população mundial, este desenvolvimento irá melhorar sensivelmente a condição de vida, libertando-a do excessivo trabalho e esforço físico de sobrevivência, permitindo que desenvolva seu potenci- al humano de maneira plena. (Crawford 1994, p.17).

Todavia, essas mudanças, num quadro profundamente otimista de modernidade, parecem estar ainda distanciadas dos países do terceiro mundo e de enormes contigentes populacionais para os quais satisfação de necessidades básicas como: educação, saúde e trabalho estão muito distantes de se tornarem realidade.

No Brasil, a gestão de recursos humanos ainda não atingiu o patamar necessário, em termos de qualificação e capacitação profissional, para competir em um mercado global onde o conhecimento e as funções altamente especializadas funcionam como o grande diferencial qualitativo aliado às novas tecnologias. Um exemplo disso é o nível de exigência cada vez maior percebido nas empresas para contratação de pessoal, o que tem deixado boa parte dos brasileiros fora do mercado de trabaIho, mesmo diante de uma vasta gama de oportunidades que surge marcada por novas formas de organização técnica e social do trabalho e do capital no contexto da economia global.

Buscar formas para que, através de visões estratégicas, tais problemas possam ser minimizados ou mesmo superados no interior das diversas teorias e práticas modernizadoras sobre a temática do conhecimento, da tecnologia, da informação e do capital humano para o crescimento econômico significa reunir forças que evidenciem 
resultados concretos em torno da qualidade de vida mundial, abrindo caminhos não só a inovações tecnológicas, mas, principalmente, às implicações educacionais (formal ou informal), desses novos paradigmas científicos e organizacionais onde investimentos em inteligência, conhecimento e informação tornaram-se o grande fator de crescimento mundial.

\section{CONCLUSÃO}

A transição da sociedade industrial para a sociedade do conhecimento é pontiIhada por inovações extraordinárias, por evolução tecnológica, por avanços na capacidade de pensar e de criar do homem, bem como na formação de parcerias empresariais e na orientação para a qualidade de produtos e serviços e do atendimento das necessidades dos clientes internos e externos.

As novas tecnologias de informação, o capital humano e gestões estratégicas compreendem os principais fatores de competitividade, diferencial e adequação à modernidade ou sociedade do conhecimento. Nesse sentido, empresas do mundo inteiro têm buscado um enfrentamento dessas questões investindo na inteligência, em novos talentos e em alta tecnologia. Esses processos levam à criação e ao desenvolvimento de estratégias de competitividade, à geração de novas idéias e ao crescimento econômico à medida que condições são propiciadas.
Uma das características marcantes da sociedade do conhecimento é o monitoramento do ambiente macroeconômico devido às constantes mudanças ambientais e estruturais, bem como a mudança de mentalidade e o nascimento de novos valores, padrões e costumes.

É tempo de informação e de transform-ação, de valorização do ser humano e da conquista de novas idéias e ideais. Organizações que não estejam dispostas a investir em novos tempos terão pouquíssimas chances de se tornarem competitivas nesse novo cenário econômico e social.

\section{BIBLIOGRAFIA}


BELASCO, James A., ATAYER, Ralph C. O Vôo do búfalo: decolando para a excelência, aprendendo a deixar os empregados assumirem a direção. Rio de Janeiro : Campus, 1994.

CRAWFORD, Richard. Na era do capital humano. São Paulo : Atlas, 1994.

FREIRE, Paulo. Pedagogia da esperança: um reencontro com a Pedagogia do Oprimido. 3.ed. Rio de Janeiro : Paz e Terra, 1994.

KEEN, Peter G. W. Guia gerencial para a tecnologia da informação. Rio de Janeiro : Campus, 1996.

O LIDER do futuro: visões estratégicas e práticas para uma nova era: 3 ed. São Paulo : Futura, 1996.

McGEE, James, PRUSAK, Laurence. Gerenciamento estratégico da informação. Rio de Janeiro : Campus, 1994.

NOVAS tecnologias, trabalho e educação: um debate multidisciplinar. 2.ed. Petrópolis : Vozes, 1994.

PARA COMPREENDER a ciência: uma perspectiva histórica. Rio de Janeiro : Espaço e Tempo, 1994.

SENGE, Peter M. A quinta disciplina: arte, teoria e prática da organização de aprendizagem. 12.ed. São Paulo : Best Seller, 1990.

STONER, James A. F. FREEMAN, R. Edward. Adminstração. 5.ed. Rio de Janeiro : Prentice Hall do Brasil, 1992.

WOOD JR., Thomas. Mudança organizacional: introdução ao tema. In.: . (org.) Mudança organiza- cional: aprofundando temas atuais em administração de empresas. São Paulo : Atlas, 1995. p.15-31. 


\section{Lidia Eugenia Cavalcante}

Professora do Departamento de Comunicação Social e Biblioteconomia da UFC, mestranda em História Social UFRJ / UFC.

\section{Title}

Strategic Management of Personnel in the Era of Information Technology and Globalization

\section{Abstract}

This article deals with alterations caused in the management of personnel aiming at a new global market, based on professional qualification and continued education, demands made by the knowledge society. It approaches issues concerning organizational changes based on paradigms of modernity and on the competitiveness of the world market. Considerations are made about the information market in the organizations facing the process of change and its impact upon areas of strategic managerial decisions. Thus, new information technologies, personnel, and strategic management constitute the main factors of competitiveness and adequacy to modernity.

\section{Keywords}

Personnel Management; Information Technology; Global Market; Knowledge Society

\section{Titulo}

Gestión Estratégica de Recursos Humanos en la Era de la Tecnología de la Información y de la Globalización

\section{Resumen}

Trata de las alteraciones ocasionadas en la gestión de recursos humanos para un nuevo mercado global, basadas en la capacitación profesional y educación continuada, exigencias de la sociedad del conocimiento. Aborda cuestiones referentes a los cambios organizacionales, con base en los nuevos paradigmas de la modernidad y competencia del mercado mundial. Presenta algunas consideraciones sobre el mercado de la información en las empresas en proceso de cambio y su impacto en áreas de decisiones estratégicas empresariales. Así, las nuevas tecnologías de información, el capital humano y gestiones estratégicas comprenden los principales factores de competencia y adecuación a la modernidad o sociedad del conocimiento.

\section{Palabras-Clave}

Gestión de recursos humanos; Tecnología de la información; Mercado global; Sociedad del conocimiento.

Artigo recebido em: 30/04/98 